\title{
The new paradigm of virtual enterprises and application of flexible production systems
}

\author{
Alexander Rementsov ${ }^{1, *}$, Vitaly Lukinov ${ }^{2}$ \\ ${ }^{1}$ Association of Innovative Regions of Russia, 12, Presnenskaya nab., 123112, Moscow, Russia \\ ${ }^{2}$ Moscow State University of Civil Engineering, 26, Yaroslavskoye Shosse, 109377, Moscow, Russia
}

\begin{abstract}
The article describes the use of flexible project management approaches during the formation of virtual enterprises. The article is devoted to the consideration of modern approaches to the definition of the concept of "virtual enterprise with a flexible production system." The study used several methods: generalization, systematization, formalization, logical, formal methods, as well as comparative analysis methods to study modern approaches of the definition of the studied concept. The tasks considered in the article are theoretical. The economic content of the concept of "virtual enterprise and flexible production system" is disclosed.The article presents the current economic content of the concept of "Flexible production system" based on a review of modern approaches to the definition of this concept, and also highlights key indicators for the implementation of a flexible production system. The basic concepts, ideas, methods of creating virtual enterprises are formulated. A new technology for the implementation of management tasks based on system design, control theory, business process and intelligent modeling were proposed $[2,3]$.
\end{abstract}

\section{Introduction}

Nowadays, consumption markets are becoming more complex, and their influence has increased even more, product life cycles have become shorter, economic cycles faster, and even a monopoly organization cannot feel safe in the market. In modern production conditions, enterprise can be a successful monopolist in ideas, innovative technologies and ways of organizing production, rather than just producing products that meet standards. Fluctuations in financial and commodity markets, the regional economic situation, the rapid change in consumer tastes of customers - all this leads to total pressure on manufacturers and makes them change in everything - from technology and labor resources to the way and approaches in managing, organizing and optimizing production, as well as to digitalization and the transition to virtual enterprises [4].

The digital transformation of enterprises is becoming a key factor in increasing competitiveness and production efficiency. This requires the use of new information technologies for managing machine systems and supporting the network interaction of people-operators of the production system using artificial intelligence [5]. From the point of

\footnotetext{
*Corresponding author: Arementsov@yandex.ru
} 
view of potential, it is most advantageous to join international chains, which over the years have accumulated traditional and modern experience in the development of the production system, a unique production culture [6].

\section{Materials and methods}

The study uses several approaches: generalization, systematization, formalization, logical, formal methods, as well as comparative analysis methods to study modern approaches to the definition of the studied concept. The tasks considered in the article are theoretical.

Systematic literature review was conducted using the databases - Google scholar and Scopus. Emphasis wason the most recent publications, especially from $2011-2019$, even though most of the literature was found before 2010. Only peer-reviewed articles such as journal articles, conference proceedings and book chapters were considered. Initial selection of articles included references about 'manufacturing enterprise information systems', 'ERP', 'MES', 'MOM', 'advanced industrial automation', 'Industry 4.0', 'smart factories' and 'smart manufacturing' [7].

In the subsequent section, findings are discussed and finally, the conclusions are drawn (where research gap was also identified for further research in future).Case research allows the study of the phenomenon in its natural context allowing good use of existing experiences. It allowed the study to reconcile the evidence from observations and data, with research literature. Qualitative synthesis of the 15 eligible (eligibility based on their links to Virtual Enterprises and flexible production systems) articles was done to write about application of flexible production systems as an instrument of the new paradigm of virtual enterprises. Given the requirement to generalize, thematic coding and analysis was done to draw the conclusions. Every section of this paper is written based on the qualitative methodology of literature review.

\section{Results}

For decades, Toyota's experience has shown that efficiency can be achieved without unnecessary material costs in a fairly short time, which has spurred many enterprises around the world to implement flexible production systems. But, nevertheless, there are a lot of examples of unsuccessful implementation. The reason for the failure to implement the concept, according to many experts, is that companies introduced a separate tool or method but did not build the production system as a fundamental and basic approach to production life.

The next generation manufacturing systems (NGPS) will be the basis for the next generation manufacturing enterprises (NGME). Adaptive distributed manufacturing systems are becoming a promising solution for NGME to provide increased levels of flexibility, reconfigurability, and intelligent equipment to meet highly dynamic market requirements. Virtual enterprises (VE) are expected to be the dominant model of a manufacturing enterprise in the 21 st century. VE promise new opportunities when the production system is not known in advance and must be structured, optimized and implemented from scratch, for example, for the production of unique products. VE can be applied to each industrial project with the help of specialized production systems, which are a temporary integration of processes and resources from several enterprises in order to meet or exceed customer requirements for quality, time and cost. The VE paradigm represents the future of NGME and can also be used to provide industrial services in a collaborative way to move from physical products to the concept of expanded products [8]. 
Next-generation products and services should ensure high quality, be widely available, offer quick and individual solutions for customers, including the ability to provide services that meet the following parameters: real-time provision, diagnostics, security, etc. (Myers, 2006)

All these trends drive the requirements and developments for the Next Generation Manufacturing Systems (NGMS) towards six grand challenges that imply:

Achieving concurrency in all operations in order to reduce products time-tomarket at the same time that products lifecycle tend to shrink [Lean Enterprise]

Instantaneously transforming information gathered from a vast array of diverse sources into useful knowledge for supporting effective decisions-making by humans and machines across the product lifecycle. This is based-on real-time information flows that enable enterprise capabilities for concurrent manufacturing [Totally Connected Enterprise].

Reconfiguring manufacturing enterprises [VE creation] rapidly in response to changing needs and opportunities in order to become a flexible enterprise with adaptable, integrated processes and systems readily reconfigurable.
Integrating human and technological resources to enhance workforce performance in order to operate as a customer-responsive enterprise and continuously improve management of product variety, product complexity and product manufacturing processes as a source of competitive advantage.

Reducing production waste [resources conservation] and products environmental impact [substitution of hazardous substances and materials] to "near zero" in order to become an environmentfriendly and sustainable manufacturing enterprise.

Developing innovative manufacturing processes and products with a focus on decreasing dimensional scale

[miniaturization] in order to design and manufacture new materials and components that will enable the manufacture of innovative, customized, waste-free products (NRC, 1998; IMS, 2000; IMTI, 2000; IPTS, 2003).

Fig. 1. Six grand challenges for NGMS development.

This paper focuses on the VE paradigm as a promising enterprise model that allows "the rapid, inexpensive and robust assembly of geographically distributed but electronicallylinked modular manufacturing units into a 'virtual factory', and the configuration or reconfiguration of cost-efficient/flexible/responsive manufacturing systems through collaborative and distributive design, resource and production planning and scheduling to manufacture high value-added products" (I*PROMS, 2006) $[9,10]$.

Virtual enterprises are the one of the new organizational forms of enterprises. The development of these forms of organization and management of the enterprise was largely influenced by such trends in the development of modern markets as their globalization, increasing importance of product quality, its price and degree of customer satisfaction, increasing the importance of sustainable relationships with consumers (individualization of customer service), and growing importance use of new information and communication technologies. Some authors call virtual enterprises "network enterprises." As a rule, we are talking about a network of partners (enterprises, organizations, individual teams and people), jointly developing, manufacturing and marketing products. 


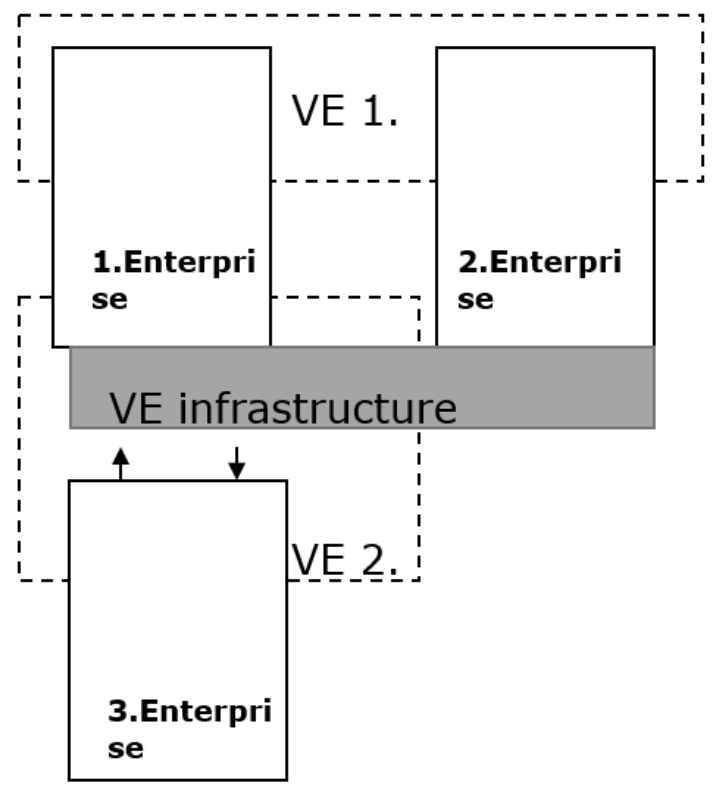

Fig. 2. VE Structure.

VE represent a "new strategic logic" where managers must be able to mobilize and manage processes and resources, rather than own them (Normann, 2001).VE is a distributed network of digital and smart factories, services and component suppliers. The combination of all organizational, technological and logistics processes can further reduce costs.

Another definition of VE can be formulated as follows - Virtual Corporation - a community of geographically separated workers who communicate, interact in the process of work, using electronic means of communication with little or no personal, direct contact [11].

Enterprise virtualization space includes:

- virtual market (market of goods and services, existing on the basis of communication and information capabilities of global networks);

- virtual reality, i.e. display and imitation of real developments and production in cyber space, which is both a tool and a development environment;

- virtual (network) organizational forms.

From a marketing point of view, the goal of a virtual enterprise is to make a profit due to maximum customer satisfaction in goods (services) by combining the resources of various partners into a single system. Virtual enterprises, as a rule, are oriented not toward satisfying the needs and requirements of the "average" customer or market segment, but rather at satisfying the individual needs of specific consumers.

From a practical point of view, a traditional enterprise, for example, requires the development of significant resources to develop and launch a new product on the market. In contrast, a virtual enterprise is looking for new partners with resources, knowledge and abilities corresponding to market needs for the joint organization and implementation of this activity. At the same time, enterprises (organizations, individual groups, and people) are selected that have key resources to achieve a competitive advantage in the market.

As a rule, a partnership is concluded for a certain period or until a certain result is achieved (for example, order fulfillment). In other words, the partnership is temporary and at certain stages of the product life cycle or when the market situation changes, new partners may be attracted to the network or old ones may be excluded. Naturally, partner enterprises for the effective functioning of the entire network should be based on a 
coordinated business process. When combining a large number of enterprises, besides geographically dispersed, the coherence of the economic process can be achieved only through the use of a single network information system based on the widespread use of new information and communication technologies. Based on the foregoing, one can highlight the key advantage of virtual enterprises: the ability to choose and use the best resources (information, financial, material, intellectual) offered by the global economic space.

The characteristic features of virtual enterprises are:

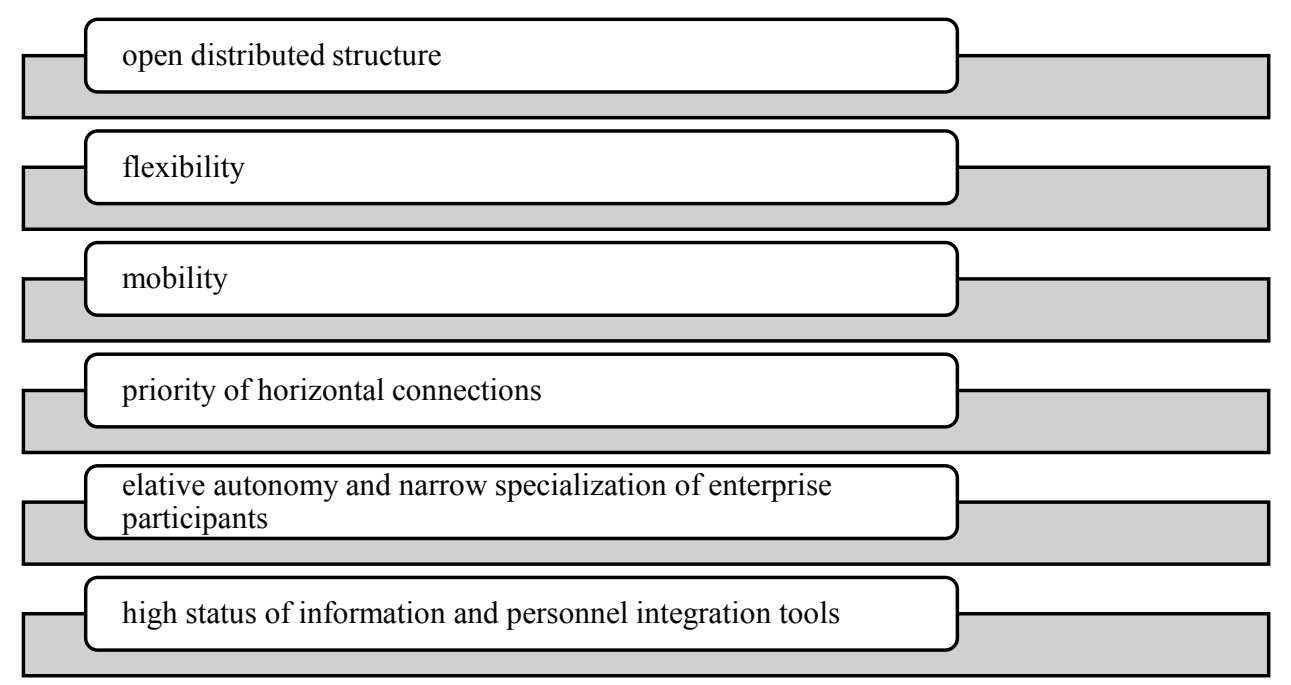

Fig. 3. Six characteristic features of VE.

Characteristics of VE are determined by the requirements of flexibility, adaptability, agility, cooperation and integration. Virtual Enterprise has several characteristics that distinguish it from a conventional one. The most unconventional characteristic is its virtuality. A Virtual Enterprise lacks many of the management and facility structures of a conventional business even if it can work like a conventional business. Another important characteristic is the adaptability of the enterprise activities- it must be able to change according to market and customer demands.

Virtual Enterprise must be created for temporary alliance therefore it is cost effective. Investments in personnel and facilities are optimized. It evolves and dissolves over time. Virtual Enterprise forms in order to elaborate a project, and disbands when the project is complete. The use of ICT plays a vital role in the Virtual Enterprise. It is not limited geographically. Employees may be located anywhere in the world and still can support the organization effectively. Virtual Enterprise use ICT tools and methods, client workplaces, servers, data warehouse, cooperation platform, services and Internet protocol. 


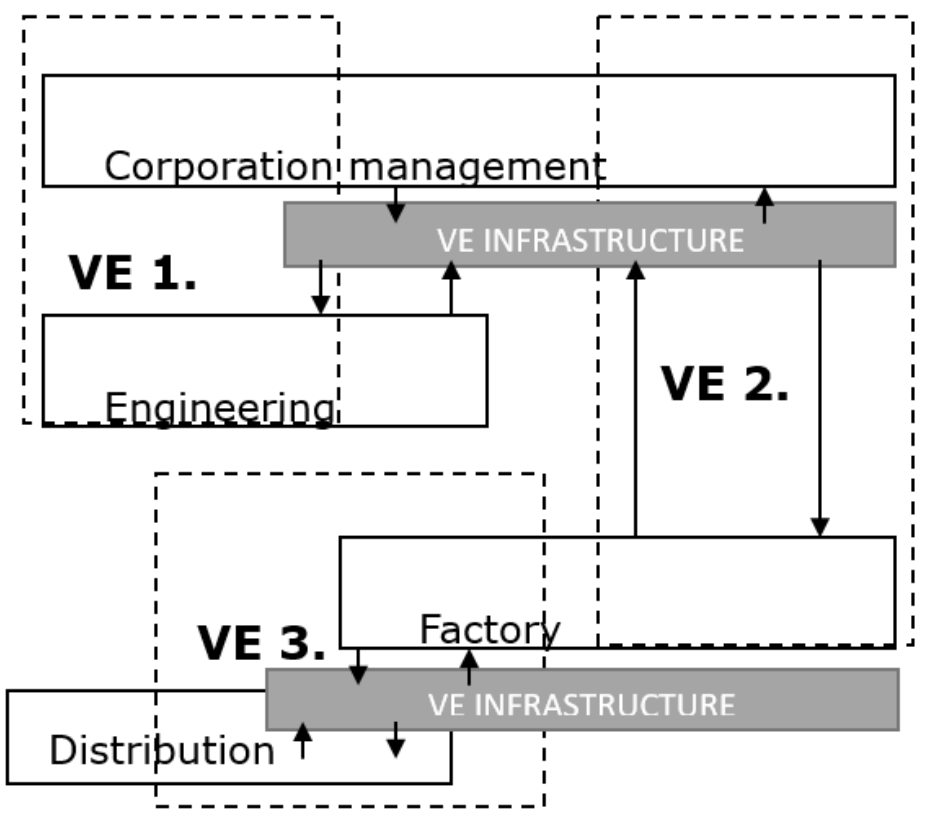

Fig. 4. Virtual Enterprise as extended CIM paradigm.

$\mathrm{VE}$ is a continuous cooperating system of autonomous functional organisations (settlements, departments, factory units) based upon electronic information processing and organisational integration.

It enables participating organisations to operate shared resources in an effective way, without any considerable extension of the resources available physically at the individual organisations.

In this formulation $\mathrm{VE}$ is mainly a comprehensive paradigm of integration within a corporation.

One of the most important advantages of VE is a sharp reduction in the amount of startup capital to establish a new business, since most of the necessary resources will be attracted on a contract basis and paid as services are provided. Another advantage is a significant reduction in the time required to prepare for the implementation of the next project. Obviously, for planning, organizing and coordinating the activities of a virtual enterprise, appropriate management approaches are also needed. An organization specializing in the creation of virtual enterprises needs to concentrate more on attracting, coordinating and managing the resources of contractors. Based on this, it is possible to formulate in general terms the basic functions of managing a virtual enterprise as a network of partners:

- definition of requirements (tasks) of the project;

- search and assessment of possible partners (performers);

- the selection of performers who are optimally suited to the tasks;

- attraction of performers and distribution of work;

- continuous monitoring and management of partners, including the redistribution of resources and tasks between them as necessary.

Along with the advantages listed above, virtual enterprises also have disadvantages:

- excessive economic dependence on partners, which is associated with the narrow specialization of the participants in the enterprise; 
- the practical lack of social protection and material support for partners (in a situation of interaction with individuals) due to the rejection of the classic long-term contractual forms and ordinary labor relations;

- the danger of over-complication arising from the heterogeneity of the participants in the enterprise, the uncertainty regarding membership in it, the dynamics of selforganization, the uncertainty in planning for participants, etc.

In other words, the principles of virtual organizational forms predetermine a decrease in the participants' autonomy and transparency of the production process. Obviously, the rejection of proven organizational and managerial principles needs substitutes. Since the legal framework for regulating the features of this type of activity is currently lacking, virtual enterprises have in some cases limited themselves to such substitutes as network culture, creating a climate of mutual trust, etc. The process of developing virtual enterprises is characterized by a lag in fundamental scientific research from practical experience. Although the success of many functioning virtual enterprises is obvious, in a wider context, many questions of their organization and functioning remain open [12].

The product of the VE is a virtual model of all organizational, technological, and logistic processes of geographically distributed "digital" and "smart" productions, presented to the user as a single object. Evaluation of the general effects of the introduction of the $\mathrm{VE}$ in comparison with traditional models of production and design: 2-4-fold increase in predictability; $40 \%$ cost reduction; reduction in the number of pieces of equipment - $7-15 \%$ (established empirically in the implementation of a comparable advanced project - GE Brilliant Factory) [13, 24, 25].

In the upcoming years we will see the following picture: the manufacturer receives a digital model of a new product, depending on the model in the production environment, it is independently configured to release of this product.Some call this scenario "a selforganizing process for the manufacture of custom-made pieces." Such an approach will lead to a revival of production; therefore, it is strongly supported by government funds, and is also promoted by market forces and meets global trends in technology development. In Germany, the new concept is called Industrie 4.0. In the United States, the Coalition of Leading Smart Manufacturing Enterprises deals with these issues.

Digital manufacturing provides a wealth of virtual design and process assessment capabilities. In the PLM Software developed by Siemens digital production support environment, which includes solutions for technological preparation and production management, real objects are presented in the form of virtual models. Digital solutions and techniques are used to design real technological systems, including the development of control logic. The result is a fully functional virtual process model that combines various engineering disciplines: tooling design, technology development, supply tasks and product quality management. Numerical modeling tools allow you to control and optimize technological processes, equipment and control algorithms, as well as the interaction between them. All this is first performed in a virtual environment, and only then it is implemented on production sites [22,23].

The next stage after digital production is a digital factory, which includes a number of additional technologies. The digital factory has an infrastructure for exchanging data with various devices, which allows you to identify situations where such an exchange really benefits and does not interfere with work, as well as software systems that analyze huge amounts of information.

To show where Digital Factory's solution is on the road to autonomous production, we'll first look at how process agility is being enhanced - a critical aspect of the new approach. In traditional production, the sequential execution of processes at various production sites is applied (conveyor principle). Each section performs a separate operation in a given sequence. 
Digital Factory solutions enable a flexible manufacturing process when the sites form a different sequence for the release of each product instance. Such a production system is better adapted to changes and allows the creation of a wide variety of technological routes (simultaneous production of several products, mass production ...).

The software product optimizes the use of technological equipment on the basis of continuous monitoring and analysis of the production situation, as well as operational decision-making. Such optimization extends both to tangible assets (machines, stocks, consumed electricity), and to intangible ones, for example, order fulfillment periods.

Event-driven numerical modeling (better known as discrete event modeling), which has already been implemented, will play an increasingly important role as the primary means of supporting autonomous production. The fact is that behind the flexibility and autonomy are the strict rules that the production system must comply with.

As shown in Fig. 5 for illustrating the design and management methodology of digital manufacturing and assembly systems in the Industry 4.0 era, the high-level Industry 4.0 design principles are followed by the Reference Architecture Model I4.0 (RAMI4.0), and then by the low-level Implementation of Manufacturing/Assembly Systems. That is to say, this methodology starts at the high-level design principles that are abstracted from RAMI4.0, which is in turn abstracted from the specific implemented manufacturing/assembly systems [14, 21].

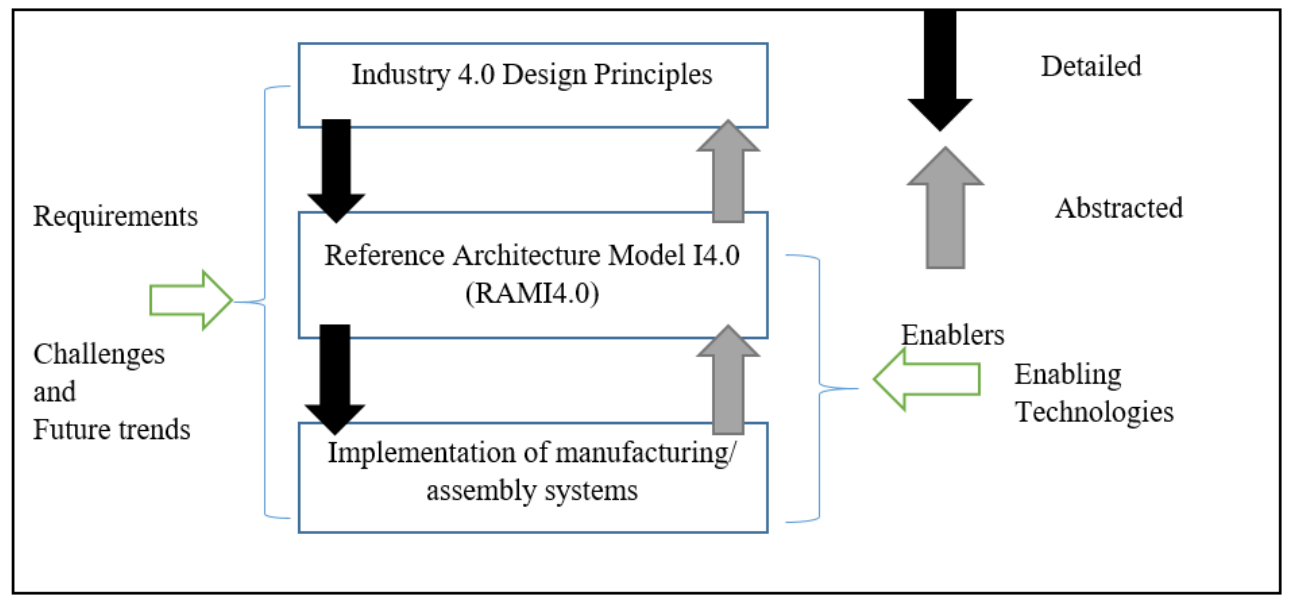

Fig. 5. Design and management of digital manufacturing and assembly systems in the Industry 4.0.

Researchers worked in defining the new manufacturing and assembly paradigms in the I4.0 era, defining its implementation conditions and technologies along with future research agenda as consequence of a new developing digital production system. On the other hand, scientific research lacks of contributes describing novel automation technologies, ICT infrastructures, control algorithms, optimization models or industrial case studies for the new generation of digital manufacturing and assembly systems which distinguish I4.0 era.

\section{Conclusions}

The global trend that will determine the development of industry in the coming years will be increased competition between developed and developing countries in the framework of global value chains. Digitalization and mass automation of production are gradually depriving developing countries of their main competitive advantage in the past - cheap labor. If robots can work faster, cheaper and more efficiently than humans, the share of 
design, design and innovation in the overall value-added structure of a product grows, and it becomes profitable for transnational corporations to return production back to their homeland (this process is called resoring).

At the same time, innovative development follows a cross-industry principle, since individual technologies and traditional highly specialized approaches are no longer able to solve the complex problems that arise in the production sphere, and the best result is provided by a combination of advanced technologies. It also creates opportunities for the successful transfer of end-to-end technological solutions from one industry to another [15, $20,26]$. The manufacturing environment radically changed over the last decades. These changes are still in progress and are a result of integrating numerous breakthrough innovations in various technologies, such as big-data analytics. At the enterprise of the future, it will not be about "automation for automation", or "integration for integration." The ultimate goal is to increase productivity and bring more products to market. Thanks to this, the enterprise will be able to implement more projects, which, in turn, will create new jobs $[16,27]$. A number of new paradigms have emerged in recent years in an attempt to describe the requirements and characteristics of the next generation of manufacturing and assembly systems. More often than not, these paradigms are used as synonymous in describing the next generation of manufacturing and assembly systems. This article assessed the challenges faced nowadays by assembly and manufacturing systems and it focused on the most promising future developments and evolution of such production systems as well as their digitalization.

The current industrial environment is distinguished by the adoption of novel production paradigms, often overlapped or competing with each other, along with the development of radical innovations resulting in several promising enabling technologies. Furthermore, this environment is distinguished by the massive digitalisation of manufacturing and assembly processes which generate at high velocity a huge volume of data distinguished by a wide variety which could be leveraged to benefit of their hidden but remarkable value. All these aspects result in several challenges faced by current production systems. The process of evolution to a truly virtual enterprise is likely to be very lengthy, since it requires numerous changes in current practice that exists in many areas of activity $[17,18,19]$.

Some dynamically developing companies serving traditional enterprises are already virtual organizations and thereby push their customers to restructure their own activities. If they fulfill their service contracts, this new area will become very similar to a virtual enterprise, with the difference that the units will have greater autonomy.

\section{References}

1. L.A. Timashova, T. Vitkovsky, Computer and Information Sciences. Bulletin of NTU "KhPI" 32(1141) (2015) ISSN 2079-0031

2. E. Ganebnykh, O. Fokina, V. Lukinov, E3S Web of Conferences 135, 04049 (2019) DOI: $10.1051 / \mathrm{e} 3$ sconf $/ 201913504049$

3. V.A. Mizyun, S.A. Ishkildina, S.A. Evdovskaya, Newsletter of the Saratov State SocioEconomic University. Digital production: distinctive characteristics and prospects for the development. Tolyatti Academy of Management, elibrary.ru/item.asp?id=42440236

4. "Production Management". About the past, present and future of production systems: from Japan to Russia, http://www.uppro.ru/library/production_management/systems/ot-yaponii-do-rossii.html

5. S. Mantravadia, Ch. Mollera, Manufacturing 30, 588-595 https://www.sciencedirect.com/science/article/pii/S2351978919301155 
6. A. Molina, D. Romero, M. Hincapié Montoya, R.J. Rabelo, 13th IFAC Symposium on Information Control Problems in Manufacturing, Conference Proceedings 31, 634-641 (2009) DOI: 10.3182/20090603-3-RU-2001.00105

7. https://www.perfekt.ru/lexikon/virtualnoe-predpriyatie/

8. Virtual enterprises (2016) http://www.logists.by/library/view/virtyalnye-predpriyatiya

9. Results of the webinar: How can Virtual factories increase the efficiency of industrial enterprises? (2020) https://technet-nti.ru/news/7304

10. Y. Cohen, M. Faccio, F. Pilati, Int J Adv Manuf Technol 105, 3565-3577 (2019) https://doi.org/10.1007/s00170-019-04595-0

11. A. Mottaeva, E3S Web of Conferences 110, 02164 (2019) doi.org/10.1051/e3sconf /201911002164

12. https://sapr.ru/article/24451

13. https://www.osp.ru/os/2000/04/177994

14. http://www.aup.ru/books/m92/12_3.htm

15. W. Davidow, M. Malone, The Virtual Corporation: Structuring and Revitalizing the Corporation for the 21st Century (New York, Harper Collins, 1992)

16. E. Ermilova, H. Afsarmanesh, Pervasive Collaborative Networks, IFIP 283, 3-14 (2008)

17. J. Hodík, J. Vokrinek, R. Hofman, Innovative Production Machines and Systems, 8590 (2007)

18. V. Holodkova, A. Mottaeva, T. Pokrovskaya, E3S Web of Conferences 164, 11043 (2020) https://doi.org/10.1051/e3sconf /202016411043

19. I. Karvonen, L. Salkari, M. Ollus, Establishing the Foundation of Collaborative Networks, IFIP 243, 253-262 (2007)

20. A. Rementsov, N. Lebedeva, O. Kirichenko, E3S Journal, TPACCEE conference 164, (2020)

21. S.S. Msanjila, H. Afsarmanesh, International Conference on Information Technology for Balanced Automation System (BASYS) 266, 95-105 (2008)

22. A.V. Bataev, A.B. Mottaeva, E.Y. Vasilyeva, Proceedings of the 34th International Business Information Management Association Conference (IBIMA)-2019, Vision 2025: Education Excellence and Management of Innovations through Sustainable Economic Competitive Advantage 14015, 277-287 (2019)

23. A.V. Sigarev, M.E. Kosov, O.B. Buzdalina, R.A. Alandarov, I.N. Rykova, European Research Studies Journal 21(1), 542-55 (2018)

24. M. Dorofeyev, M. Kosov, V. Ponkratov, A. Masterov, A. Karaev, M. Vasyunina, European Research Studies Journal 21(3), 429-445 (2018)

25. V.A. Slepov, V.K. Burlachkov, T.P. Danko, M.E. Kosov, I.I. Volkov, O.A. Grishina, V.D. Sekerin, European Research Studies Journal 20(4A), 488-500 (2017)

26. Y.V. Morozyuk, A.V. Sharkova, I.A. Merkulina, O.N. Vasilyeva, Journal of Environmental Management and Tourism 8.3(19), 507-515 (2017)

27. I.A. Markina, A.V. Sharkova, M.Y. Barna, International Journal of Entrepreneurship 22(3) (2018)

28. N.Y. Ryazanova, A.V. Sharkova, N.E. Lobzhanidze, E.V. Subbotina, O.E. Matyunina, International Journal of Recent Technology and Engineering (2019) 
29. S. Rakhimova, K. Kunanbayeva, L. Goncharenko, A. Pigurin, E3S Web of Conferences 110, 02154 (2019) https://doi.org/10.1051/e3sconf/201911002154

30. K. Kunanbayeva, A. Gorovoy, A. Butyrin, MATEC Web of Conferences 193, 05048 (2018) https://doi.org/10.1051/matecconf/201819305048 